(The 3rd ICBS-2013)

\title{
CHROMOSOME NUMBER AND TIME PERIOD OF MITOTIC CYCLE OF FESTIVAL AND CALIFORNICA STRAWBERRY CULTIVARS (Fragaria $x$ ananassa AND Fragaria vesca)
}

\author{
Ganies Riza Aristya, Rezika Alyza, Rosyidatul Khoiroh and Budi Setiadi Daryono \\ Genetics Laboratory, Faculty of Biology, Universitas Gadjah Mada \\ Teknika Selatan Street, Sekip Utara Yogyakarta 55281 \\ e-mail of correspondence : ganies_riza@ugm.ac.id
}

\begin{abstract}
The cultivated strawberries, Fragaria $x$ ananassa and Fragaria vesca, are the most economically-important softfruit species. $F x$ ananassa and $F$ vesca, both diploid $(2 n=2 x=14)$ relatives of the commercial octoploid strawberry, are an attractive model for functional genomics research in Rosaceae. Its small genome size, short reproductive cycle, and facile vegetative and seed propagation make F. x annassa and F.vesca a promising candidates for forward and reverse genetics experiments. In order to determine their genetic differences in more detail, chromosome characterization of the two strawberry cultivars was investigated. A method used for chromosome slides in this research was a squash method with modification in pre-treatment. The result showed Fragaria $x$ ananassa had $(2 n=4 x=28)$ chromosome number is 28 and Fragaria vesca had $(2 n=2 x=14)$ chromosome number is 14 . The time of mitotic that both strawberry cultivars was similar at 7 to $8.30 \mathrm{am}$. In addition, mixoploid cells were found in both strawberry cultivar indicating that these cultivars had been treated by mutagenic agents for a breeding program.
\end{abstract}

Key words : Fragaria, chromosome, mitotic

\section{INTRODUCTION}

The cultivated strawberries, Fragaria $\mathrm{x}$ ananassa and Fragaria vesca, are the most economically important soft fruit species and belong to the Rosaceae which known to be a large and diverse family including Malus (apples), Prunus (the stone fruits and almonds), Rubus (the blackberries and raspberries), Pyrus (pears) and many ornamental species including the genus Rosa (the roses). Fragaria $x$ ananassa is an allo-octoploid species (2n $=8 \mathrm{x}=56$ ) derived from artificial hybridisation between two progenitor species $F$. chiloensis and $F$. virginiana (Darrow, 1966). The genus Fragaria has a basic chromosome number of seven $(x=7)$ (Ichijima, 1926), and four main fertility groups are recognized: the diploids $(2 n=2 x=14)$ which include the model species for the genus, F. vesca; the tetraploids $(2 n=4 x=28)$ including F. orientalis; the single hexaploid species F.moschata $(2 n=6 x=42)$; and four octoploid species $(2 n=8 x=56)$ : F. chiloensis, F. iturupensis, F. virginiana and the hybrid cultivated strawberry, F.x ananassa. The octoploid species are thought to be allooctoploids, with a proposed genome composition of AAA'A'BBB'B' implying contributions from at least four distinct ancestral diploid genomes. However, the prior genome composition models (AAAABBCC and AAA'A'BBBB) of (Fedorova, 1946) and (Senanayake \& Bringhurst, 1967), respectively, recognized the possibility of an autopolyploid component, and the genome compositions of the octoploid species have yet to be rigorously established.

The chromosomes of Fragaria are rather small, ranging from $0.9-1.7$ microns in length (Yarnell, 1928) and display very little variation in morphology between species (Iwatsubo \& 
Naruhashi, 1989). Ichijima (1926) studied the cytology of Fragaria chromosomes at various levels of ploidy. In the diploid species, no irregular chromosomal behavior was observed in the course of heterotypic division and the 14 somatic chromosomes were clearly seen and could be readily counted at metaphase. In the octoploid Fragaria, it was difficult to count the somatic chromosomes because of the closely and irregularly packed character. The count was best done during late diakinesis. Chromosome number in these experiments could not be determined definitely, but it was reported that it appeared to be 56 , which would be expected for an octoploid species with a haploid chromosome number of $x=7$. Byrne \& Jelenkovi'c (1976) observed only bivalents in meiotic spreads from nine cultivated genotypes. More recently, (10) applied fluorescent in situ hybridization (FISH) to F. vesca using the $45 S$ and $5 S$ rRNA genes, which revealed six $45 S$ and two $5 S$ sites within the 14 somatic chromosomes of $F$. vesca. The experiments of (Lim, 2004) enabled the construction of an $F$. vesca karyotype with three pairs of marker chromosomes, but the technique has yet to be extended to the genetically and cytologically more complex genomes of the octoploid Fragaria species. In order to determine their genetic differences in more detail, chromosome characterization of the two strawberry cultivars was investigated.

\section{MATERIALS AND METHODS}

\section{Plant material}

$F . \mathrm{x}$ ananassa and $F$. vesca accessions used in this study was obtained from the Banyuroto Agrotourism at Sawangan Magelang, Central Java. Seedlings were taken from young plants that germinated from one month old of stolon.

\section{Chromosome preparation}

Root tips from germinating seedling from field-grown was used for chromosome preparation. Seedling germination from $F$. $x$ ananassa and $F$. vesca was conducted in a growth chamber maintained at $25^{\circ} \mathrm{C}$. Germinating root of stolon derived from seedling with $1-$ to 5 - $\mathrm{mm}$ radicles and cutted at root tip. The root tips were placed in freshly prepared $45 \%$ glacial acetic acid and stored in a refrigerator for at least $15 \mathrm{~min}$. Subsequently, the root tips were washed three times with aquadest, and were excised and hydrolyzed in $1 \mathrm{~N} \mathrm{HCl}$ for 3 $\min$ at $56^{\circ} \mathrm{C}$. The tips were washed with aquadest three times, and then were stained in $2 \%$ aceto orcein at room temperature for $2 \mathrm{~h}$. A root was transfered to the center of a clean microscope slide and added a drop of glicerol onto the root. Using a razor blade cut off most of the unstained part of the root, and discarded it. Cover the root tip with a cover slip, and then carefully push down on the cover slide with the wooden end of a dissecting probe. Push hard, but do not twist or push the cover slide sideways. The root tip should spread out to a diameter about $0.5-1 \mathrm{~cm}$.

\section{RESULTS AND DISCUSSION}

Chromosomes consider small in all Fragaria species, and only minor variation in chromosome morphology has been described (Ichijima, 1926; Senanayake \& Bringhurst, 1967; Iwatsubo \& Naruhashi, 1989). F. $x$ ananassa had tetraploid $(2 n=4 x=28)$ and $F$. vesca had diploid $(2 n=2 x=14)$ (Figure 1). Mitotic phase were obtained for prophase, prometaphase, 
metaphase, anaphase, telophase and interphase (Figure 2).
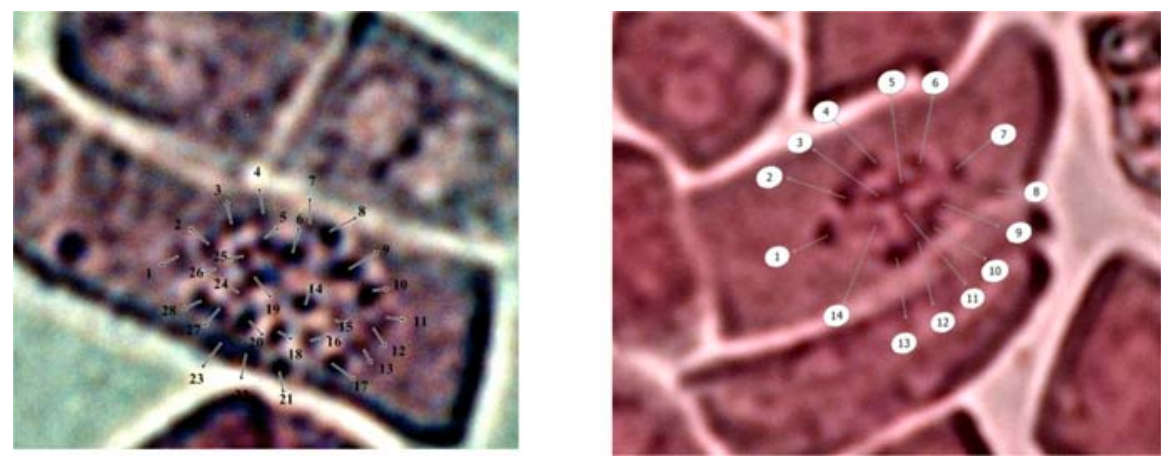

Figure 1. Chromosome number from $F$. $x$ ananassa $(2 n=4 x=28)$ (left) and $F$. vesca $(2 n=2 x=$ 14) (right). The number indicates the count of chromosome

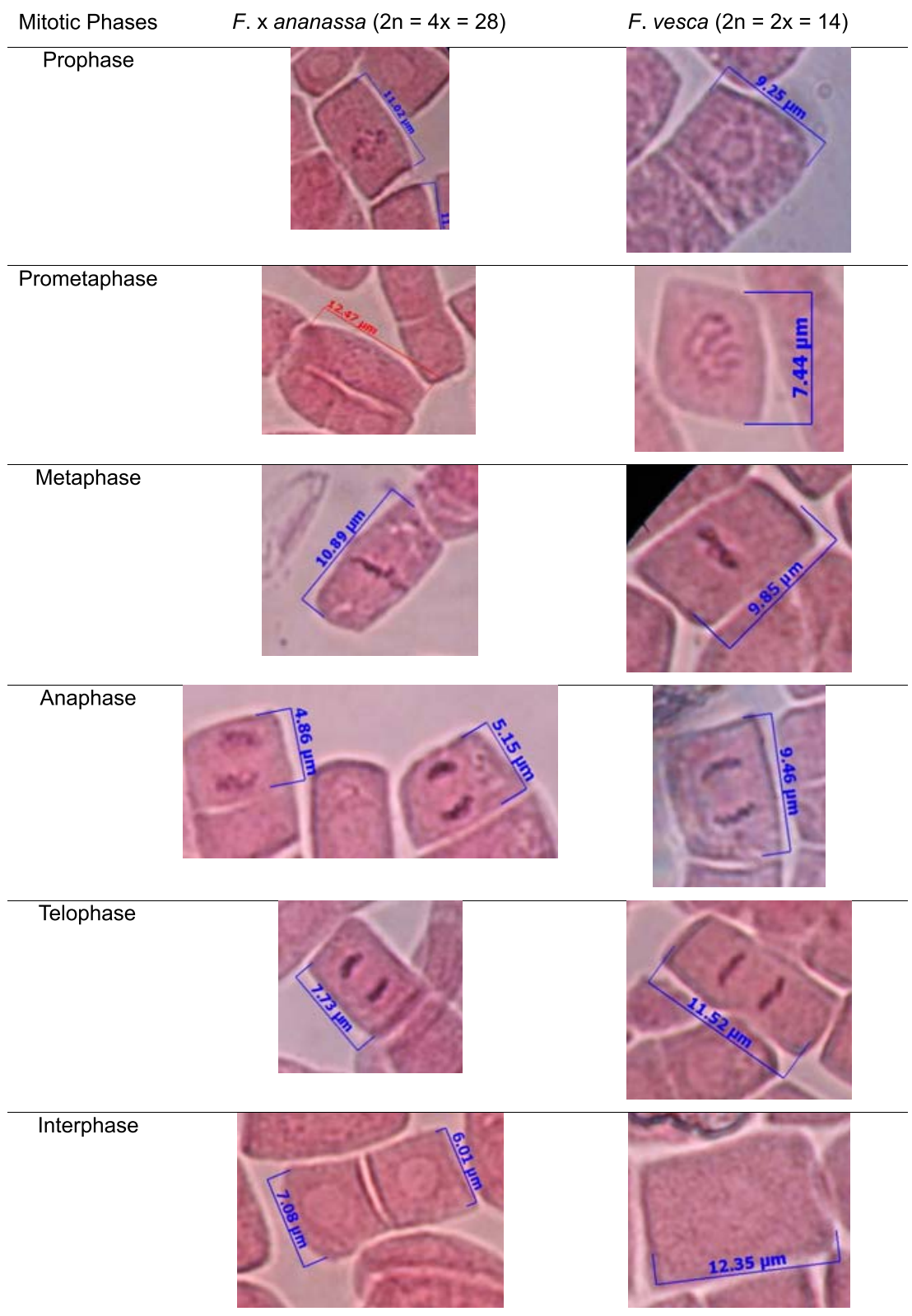

Figure 2. Mitotic phase of Fragaria $x$ ananassa (left) and Fragaria vesca $(2 n=2 x=14)$ (right). 
Time periode from F. $x$ ananassa were at $06.00-07.00$ am and F. vesca at $07.00-$ $08.00 \mathrm{am}$. The basic chromosome number in Fragaria is $x=7$ (Ichijima, 1926). The recognized Fragaria species comprises apolyploid series, including twelve diploid $(2 n=2 x=14)$ species, four tetraploids $(2 n=4 x=28)$, one hexaploid $(2 n=6 x=42$ : F. moschata), and four octoploids $(2 n=8 x=56)$. Synthetic octoploids have been constructed via controlled, interspecific hybridizations accompanied by chromosome doubling, in an effort to broaden the octoploid gene pool available to strawberry breeders (Evans, 1977; Bors, 2000). The decaploid level has been obtained in controlled crosses accompanied by chromosome number manipulation (Ahmadi \& Bringhurst, 1992; Scott, 1951). Decaploids referred to as Fragaria $x$ vescana were derived from crossing $F$.x ananassa $(2 n=56)$ with tetraploid forms of $F$. vesca var. semperflorens $(2 n=28)$ followed by backcrossing to $F . x$ ananassa (2).

\section{REFERENCES}

Ahmadi, H., and R.S. Bringhurst. 1992. Breeding strawberries at the decaploid level. JAm Soc Hort Sci 117:856-862

Bauer, A. 1993. Progress in breeding decaploid Fragaria $x$ vescana. 2nd Intl Strawberry Symp, Beltsville, Maryland, USA, 13-18 September 1992. Acta Hort348:60-64

Bors, R.H. 2000. A streamlined synthetic octoploid system that emphasizes Fragaria vesca as a bridge species. PhD Thesis, Univof Guelph, Ontario, Canada

Byrne, D., and G. Jelenkovi'c. 1976. Cytological diploidization in the cultivated strawberry Fragaria $\times$ ananassa. Canadian Journal of Genetics Cytology 18:653-659

Darrow, G.M. 1966. The strawberry: History, breeding and physiology. Holt, Rinehart and Winston, USA

Evans, W.D. 1977. The use of synthetic octoploids in strawberry breeding. Euphytica 26:497503

Fedorova, N.J. 1946. Crossability and phylogenetic relations in the main European species of Fragaria. Compilation of the National Academy of Sciences USSR 52: 545-547

Ichijima, K. 1926. Cytological and genetic studies on Fragaria. Genetics 11: 590-603

Iwatsubo, Y., and N. Naruhash. 1989. Karyotypes of three species of Fragaria (Rosaceae). Cytologia 54: 493-497

Lim, K.Y. 2004. Karyotype and ribosomal gene mapping in Fragaria vesca L. Acta Horticulturae 649: 103-106

Oosumi, T., H.A. Gruszewski, L.A. Blischak, A.J. Baxter, P.A. Wadl, J.L. Shuman, R.E. Veilleux, and V. Shulaev . 2006. High-efficiency transformation of the diploid strawberry (Fragaria vesca) for functional genomics. Planta 223: 1219-1230

Scott, D.H. 1951. Cytological studies on polyploids derived from tetraploid Fragaria vesca and cultivated strawberries. Genetics 36:311-325

Senanayake, Y.D.A., and R.S. Bringhurst. 1967. Origin of Fragaria polyploids I. Cytological analysis. American Journal of Botany 54: 221-228

Yarnell, S.H. 1928. Notes on the somatic chromosomes of the seven-chromosome group of Fragaria. Genetics 14: 78-83. 